\title{
Farinha de carcaça de Tilápia em dietas para coelhos: composição química e resistência óssea
}

\author{
Meal of Nile Tilapia carcass in diets for rabbits: chemical \\ composition and bone resistance
}

\author{
Guilherme Legnani Galan; Maria Luiza Rodrigues de Souza Franco; \\ Emilia Dorta de Souza ${ }^{3}$; Cláudio Scapinello²; Eliane Gasparino²; \\ Jesui Vergilio Visentainer ${ }^{4}$; Ana Paula Del Vesco ${ }^{1}$
}

\section{Resumo}

O experimento foi conduzido com o objetivo de avaliar as características qualitativas da carcaça e a resistência óssea de coelhos alimentados com dietas enriquecidas com farinha de resíduos de filetagem de tilápia do Nilo (Oreochromis niloticus). Foram utilizados 50 animais, distribuídos em um delineamento interamente casualizado com cinco tratamentos $(0 \%, 1 \%, 2 \%, 3 \%$ e $4 \%$ de inclusão da farinha) e dez repetições. Os valores de proteína bruta, cálcio e fósforo dos músculos dos coelhos, apresentaram efeito quadrático. Os ácidos graxos majoritários no músculo dos coelhos foram 16:0, 18:1n9 e 18:2n6. A resistência média $(23,40 \mathrm{Kgf})$ e a composição química dos ossos, cálcio $(20,36 \mathrm{~g} / 100 \mathrm{~g})$ fósforo $(0,17 \mathrm{~g} / 100 \mathrm{~g})$ e ferro $(0,17 \mathrm{mg} / 100 \mathrm{~g})$ não foram influenciadas pela inclusão da farinha. Conclui-se que a farinha de resíduos de filetagem de tilápia, influenciou nas características qualitativas da carcaça dos coelhos, porém não influenciou na resistência e na composição química dos ossos.

Palavras-chave: Ácidos graxos, farinha de peixe, minerais, Nova Zelândia Branco

\begin{abstract}
This study aimed to assess the carcass quality and bone resistance in rabbits fed with diets enriched with meal filleting residue of Nile tilapia (Oreochromis niloticus). There were 50 animals distributed in five treatments in which the diets were $0 \%, 1 \%, 2 \%, 3 \%$ and $4 \%$ for inclusion of meal. The values of crude protein, calcium and phosphorus from muscle of rabbits responded quadratically. The major fatty acids in the muscle of rabbits were 16:0,18:1n9 and 18:2n6. The average resistance (23.40kgf) and chemical composition of bones and calcium $(20.36 \mathrm{~g} / 100 \mathrm{~g})$ phosphorus $(0.17 \mathrm{~g} / 100 \mathrm{~g})$ and iron $(0.17 \mathrm{mg} / 100 \mathrm{~g})$ were not influenced by the inclusion of the meal. It was concluded that the meal of tilapia filleting residue influenced carcass quality characteristics of rabbits but did not influence the resistance and the chemical composition of bones.
\end{abstract}

Key words: Fatty acid, fish meal, minerals, New Zealand White

\footnotetext{
${ }^{1}$ Discentes do programa de Pós Graduação em Zootecnia da Universidade Estadual de Maringá, UEM, Av. Colombo, 5.790, CEP: 87020900. Maringá, PR. E-mail: g_legnanigalan@hotmail.com; apaulavesco@gmail.com

${ }^{2}$ Profs. do Dept ${ }^{\circ}$ de Zootecnia, UEM, Maringá, PR. E-mail: mlrsouza@uem.br; cscapinello@uem.br; egasparino@uem.br

${ }^{3}$ Discente de Graduação em Zootecnia, UEM, Maringá, PR. E-mail: emilia.dorta@hotmail.com

${ }^{4}$ Prof. do Dept ${ }^{\circ}$ de Química, UEM, Maringá, PR. E-mail: jvvisentainer@uem.br

* Autor para correspondência
} 


\section{Introdução}

Os coelhos são animais herbívoros que necessitam de uma dieta equilibrada de acordo com suas necessidades nutricionais. Considerando-se a grande influencia da alimentação para a viabilização da cunicultura, que representa, aproximadamente, $70 \%$ do custo total da produção de coelhos, fica evidente a preocupação dos nutricionistas e dos produtores de coelhos com a qualidade das rações para coelhos comercializadas no Brasil. Alimentos de origem animal autorizados e fermentados em geral derivados da indústria sucroalcooleira podem ser usados, mas podem interferir na palatabilidade da ração além de onerar o custo da mesma. Todavia, dentre os ingredientes utilizados de origem animal utilizada é a farinha de vísceras de aves que pode substituir em até $25 \%$ o farelo de soja. Também as farinhas de peixe e de carne e ossos podem ser utilizadas em nível de até $5 \%$ na ração (MACHADO et al., 2011). No entanto, o uso dos resíduos do pescado, neste experimento, tem objetivo de fornecer cálcio e fósforo. Em dietas de coelhos a principal fonte de fósforo mineral é o fosfato bicálcico, que apresenta elevado custo nas formulações e este poderia ser substituído por outra fonte, sendo esta de origem orgânica. Em dietas de coelhos o fosfato bicálcico normalmente é adicionado em níveis que variam de 0,5 a 1,0\%. Os dados nacionais de utilização de cálcio são de $0,50 \%$ e $0,36 \%$ de fósforo na dieta (FERREIRA et al., 2006).

Para a obtenção da farinha de peixe, grande parte do pescado processado termina sob a forma de resíduos industriais, que poderiam ser utilizados para a produção de alimentos nutritivos e de baixo custo, sendo uma alternativa viável de exploração comercial e reduzindo a geração de resíduos orgânicos. Apenas 30\% do pescado é utilizado para a produção de filé, sendo que o restante dos $70 \%$ ( $14 \%$ de cabeça, $35 \%$ de carcaça, $10 \%$ de pele e $1 \%$ de escamas, VIDOTTI; GONÇALVES, 2006), com alto valor nutricional poderiam ser incorporados na nutrição animal na forma de diversos produtos, como farinhas e silagem (EYNG et al., 2010).

Dentre as espécies de peixes cultivadas, a tilápia é a segunda espécie em volume de produção no mundo (NAYLOR et al., 2000), e a terceira em geração de renda (BORGHETTI; OSTRENSKY; BORGHETTI, 2003). É uma espécie apropriada para a indústria de filetagem, todavia, no processo é gerado uma elevada quantidade de resíduos, que segundo Boscolo et al. (2001), representam, entre 62,5 e $66,5 \%$ da matéria-prima com alto conteúdo de nutrientes, no entanto se não forem devidamente processados para uso na nutrição humana ou animal, esses resíduos têm sido desperdiçados e contribuído com impacto ambiental. A transformação destes resíduos em farinha é uma opção de renda para as indústrias, podendo aumentar sua lucratividade e incluindo em rações como excelente fonte protéica e de minerais, principalmente com cálco e fósforo.

A elaboração de farinha de peixe a partir de resíduos da filetagem de tilápia do Nilo é uma fonte protéica, trabalhos realizados por Hardy (1996), e Sugiura et al. (2000) mostraram 48,13\%; 57,50\% e $46,90 \%$ de proteína bruta, respectivamente. Godoy (2006) relata que farinha a partir de carcaças de tilápia para consumo humano apresentou 32,82\% de proteína bruta, $21,95 \%$ de lipídeos e $22,86 \%$ de cinzas. Quanto aos minerais essa mesma farinha apresentou 1,78 g de cálcio em $100 \mathrm{~g}$ de farinha, 2,36 $\mathrm{mg}$ de ferro e 5,47 $\mathrm{mg}$ de fósforo em $100 \mathrm{~g}$ de farinha de tilápia elaborada. Os mesmos autores mencionaram que foram encontrados 23 ácidos graxos e dentre eles os AGPI n-3 de grande importância como o ácido eicosapentaenoico (EPA) e o docosahexaenóico (DHA).

O objetivo do presente trabalho foi verificar as características qualitativas da carcaça (composição química e ácidos graxos), resistência óssea, teores de matéria mineral e minerais (cálcio, fósforo e ferro) dos ossos de coelhos alimentados com rações contendo níveis crescentes de farinha de peixe obtidas dos resíduos da filetagem de tilápia do Nilo. 


\section{Material e Métodos}

O experimento foi conduzido no setor de Cunicultura da Fazenda Experimental de Iguatemi, da Universidade Estadual de Maringá/PR.

Para a obtenção da farinha de resíduos de filetagem de tilápia (FRFT), foram utilizados $30 \mathrm{Kg}$ de carcaças com cabeça de tilápias do Nilo (Oreochromis niloticus), provenientes de unidades de beneficiamento Smart Fish (Rolândia, $\mathrm{PR})$. Após filetagem das tilápias, foram retiradas das carcaças, as nadadeiras e a brânquias da cabeça e submetidas a lavagem. Em seguida adicionou-se $0,01 \%$ de Butil Hidroxitolueno (BHT) e $0,05 \%$ de sorbato de potássio para cada $10 \mathrm{Kg}$ dessa matéria-prima em água para mantêlas imersas por 15 minutos, para penetração do antioxidante e antifúngico. Após foram colocadas para cozimento, por 40 minutos em temperatura de $300^{\circ} \mathrm{C}$. Decorrido esse período as mesmas foram moídas e a massa gerada foi levada para o desidratador por 45 horas a $40^{\circ} \mathrm{C}$. A farinha foi prensada em prensa hidráulica, com capacidade de 10 toneladas para retirada do excesso do óleo, seguida de nova moagem para reduzir a granulometria. Amostras das farinhas foram embaladas e congeladas $\left(-18^{\circ} \mathrm{C}\right)$ para realização das análises de composição centesimal, ácidos graxos e minerais.

Foram utilizados 50 coelhos da raça Nova Zelândia Branco, distribuídos em um delineamento inteiramente casualizado, com cinco tratamentos e 10 repetições por tratamento. Sendo o coelho considerado a unidade experimental.

Os animais foram alojados em gaiolas individuais de arame galvanizado, providas de bebedouro automático e comedouro semiautomático de chapa galvanizada, localizados em galpão de alvenaria, com cobertura de telha francesa, pé-direito de 3,2 metros, piso de alvenaria, paredes laterais de 50 $\mathrm{cm}$, em alvenaria e o restante em tela e cortina plástica para controle de ventos. Dessa forma os animais receberam alimentação e água a vontade no período de 35 a 65 dias. As rações contendo 0, 1, 2, 3 , e $4 \%$ de inclusão de farinha de peixe. As rações testemunha e com inclusão de farinha de resíduos de filetagem de tilápia, (Tabela 1) foram balanceadas de forma a se apresentarem isonutrientes, atendendo às recomendações nutricionais para coelhos em crescimento (DE BLAS; MATEOS, 1998). Foram realizadas análises de composição centesimal (umidade, proteína bruta, lipídios e matéria mineral), minerais (cálcio, fósforo e ferro) e ácidos graxos nas rações experimentais.

Os coelhos foram abatidos com 65 dias de idade. Após o abate, os animais foram avaliados quanto as características qualitativas do músculo, sendo avaliação da composição centesimal (umidade, proteína bruta, lipídios e matéria mineral), minerais (cálcio, fósforo e ferro) e perfil de ácidos graxos. Foi retirado de cada animal, o fêmur da coxa direita para as análises de resistência óssea, matéria mineral e os minerais (cálcio, fósforo e ferro).

As análises de resistência óssea foram realizadas no laboratório de Engenharia Civil na Universidade Estadual de Maringá/PR. Com auxílio do equipamento Emic DL 30006, com célula de força com capacidade de $50 \mathrm{kgf}$. As peças ósseas foram posicionadas em apoios da região das epífises e ficaram sem apoio na região central. A posição escolhida foi a antero-posterior para evitar que os ossos se deslocassem no momento da quebra (Figura 1). A força foi aplicada na região central, sempre no mesmo ponto em todos os ossos. Após a análise os valores foram corrigidos pela seguinte equação $\mathrm{Y}=0,0169 \mathrm{x}+0,0942$. Os valores foram representados em Kgf. 
Tabela 1. Composição percentual e química das rações experimentais, contendo diferentes níveis de farinha de resíduos de filetagem de tilápia do Nilo (FRFT).

\begin{tabular}{lccccc}
\hline \multirow{2}{*}{ Ingredientes } & Ração & \multicolumn{4}{c}{ Níveis de inclusão de FRFT } \\
\cline { 2 - 5 } & Testemunha & $1 \%$ & $2 \%$ & $3 \%$ & $4 \%$ \\
\hline Trigo Farelo & 24,00 & 21,76 & 19,47 & 17,18 & 14,97 \\
Milho Grão & 23,00 & 24,07 & 25,09 & 26,29 & 27,30 \\
Feno Coast Cross & 21,14 & 21,77 & 22,38 & 22,98 & 23,59 \\
Feno Alfafa & 18,00 & 18,00 & 18,00 & 18,00 & 18,00 \\
Soja Farelo (45\%) & 11,20 & 10,97 & 10,79 & 10,50 & 10,39 \\
Calcário & 1,20 & 1,05 & 0,90 & 0,75 & 0,60 \\
Sal Comum & 0,40 & 0,40 & 0,40 & 0,40 & 0,40 \\
Fosfoto Bicálcico & 0,30 & 0,23 & 0,15 & 0,08 & 0,00 \\
Mineral Coelho & 0,25 & 0,25 & 0,25 & 0,25 & 0,25 \\
Vitamina Coelho & 0,25 & 0,25 & 0,25 & 0,25 & 0,25 \\
L-Lisina & 0,14 & 0,13 & 0,13 & 0,12 & 0,11 \\
DL-Metionina & 0,06 & 0,06 & 0,05 & 0,05 & 0,04 \\
Coxistac & 0,06 & 0,06 & 0,06 & 0,06 & 0,06 \\
FRFT & 0,00 & 1,00 & 2,00 & 3,00 & 4,00 \\
\hline Composição calculada & & & & & 89,97 \\
Matéria Seca (\%) & 90,02 & 91,14 & 90,35 & 89,34 & 16,04 \\
Proteína Bruta (\%) & 16,01 & 16,02 & 16,03 & 16,04 & 14,10 \\
Fibra Bruta (\%) & 14,51 & 14,41 & 14,31 & 14,20 & 2,526 \\
Energia (Mcal) & 2,520 & 2,522 & 2,523 & 2,525 & 31,53 \\
FDN (\%) & 32,92 & 32,57 & 32,22 & 31,87 & 18,92 \\
FDA (\%) & 18,94 & 18,93 & 18,93 & 18,93 & 0,9935 \\
Cálcio (\%) & 0,9606 & 0,9688 & 0,9771 & 0,9853 & 0,4993 \\
Fósforo (\%) & 0,4802 & 0,4850 & 0,4898 & 0,4945 & 0,7982 \\
Lisina Total (\%) & 0,7981 & 0,7981 & 0,7982 & 0,7982 & 0,597 \\
Met.+Cistina Total (\%) & 0,599 & 0,598 & 0,598 & 0,597 & \\
\hline
\end{tabular}

FRFT (Farinha de resíduos de filetagem de tilápia do Nilo), FDN (Fibra detergente neutro), FDA (fibra detergetne ácido), Met+Cistina Total (Metionina + Cistina Total), Vitamina/Mineral Coelho: Nuvital super Composição por kg do produto: Vit. A, 300.000 UI; Vit. D, 50.000; Vit. E, 4.000 mg; Vit. K3, 100 mg; vit. B1, 200 mg; Vit. B2, 300 mg; Vit. B6, 100 mg; Vit. B12, 1.000 mg; ac. Nicotínico. $1.500 \mathrm{mg}$; ac Pantotênico., $1.000 \mathrm{mg}$; Colina, 35.000mg; ferro, 4.000 mg; Cobre, $600 \mathrm{mg}$; Cobalto, 100 mg; Manganês, 4.300 mg; Zinco, 6.000 mg; Iodo, 32 mg; Selenio, 8 mg; Metionina, 60.000 mg, Promotor de crescimento. 1.500 mg; Coccidiostático, $12.500 \mathrm{mg}$; Antioxidante, $10.000 \mathrm{~m}$.

Fonte: Elaboração dos autores.

Figura 1. Teste de Resistência Óssea. A - dinamômetro com o corpo de prova (Fêmur da coxa direita do coelho). B corpo de prova em detalhe na base adequada para resistência óssea.
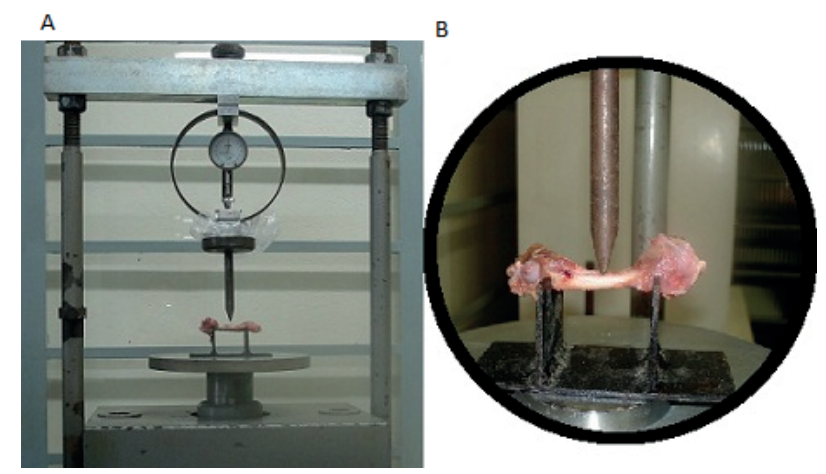

Fonte: Elaboração dos autores. 
As análises de composição química foram realizadas no Laboratório de Nutrição Animal (LANA) do Departamento de Zootecnia, na Universidade Estadual de Maringá, em que se utilizou a metodologia descrita por Cunniff (1998), para teores de umidade e matéria mineral. Para teor de proteína bruta no músculo foi empregado o método semimicro Kjeldahl descrito por Silva e Queiroz (2002).

Nas análises de cálcio e ferro, a digestão das amostras foi realizada em meio ácido e as determinações realizadas por espectrometria de absorção atômica com chama (FAAS), conforme o procedimento descrito por Zhou et al. (1998). As determinações de fósforo total foram realizadas utilizando fosfomolibdato de amônio por espectrofotometria UV-VIS, conforme Eijsink, Krom e Lange (1997).

Para a extração lipídica do músculo e das rações, foi utilizada a metodologia descrita por Bligh e Dyer (1959). A matéria graxa obtida foi quantificada em balança analítica e o teor de lipídios totais determinado por pesagem.

A transesterificação dos triacilgliceróis foi realizada no Laboratório de Química da Universidade Estadual de Maringá, conforme método da ISO 5509 (1978). Em seguida, as amostras foram armazenadas em congelador a $-20^{\circ} \mathrm{C}$, acondicionadas em ependorff, para posteriores análises cromatográficas. Os ésteres metílicos foram separados em um cromatógrafo gasoso 14-A (Shimadzu, Japão), equipado com detector de ionização de chama e coluna capilar de sílica fundida $(100 \mathrm{~m}$ x $0,25 \mathrm{~mm}$ di x $0,25 \mu \mathrm{m}$, CPSil 88). As áreas dos picos (percentagens de áreas relativas) foram integradas por um integradorprocessador CG-300 (instrumentos científicos).

As identificações dos ácidos graxos foram efetuadas pelos seguintes critérios: comparação dos tempos de retenção de ésteres metílicos de padrões da sigma (EUA) com os das amostras e comparação dos valores de ECL (Equivalent
Chain Lenght) dos ésteres metílicos das amostras com valores das literaturas de Visentainer (2003) e Silva (2000). O perfil de ácidos graxos foi realizado para caracterização do músculo e das rações dos coelhos que receberam as diferentes rações em função dos níveis de inclusão da farinha de resíduos de filetagem de tilápia, portanto não foi realizada análise estatística.

Os parâmetros de qualidade da carcaça (composição química e perfil de ácidos graxos), a resistência óssea, de acordo com os níveis de inclusão de farinha de resíduos de filetagem de tilápia foram analisados por regressão (SAS, 2000). A normalidade dos dados foi verificada pelo procedimento UNIVARIATE do SAS e a homogeneidade de variância pelo teste de Bartlett. Para as comparações entre o tratamento testemunha e os tratamentos com os diferentes níveis de inclusão de farinha de resíduos de filetagem foi realizado o teste de Dunnett considerando nível de significância de $5 \%$.

\section{Resultados e Discussão}

A farinha de resíduos de filetagem de tilápia apresentou 3,06\% de umidade, $33,80 \%$ de proteína bruta, $34,31 \%$ de lipídios, $28,96 \%$ de matéria mineral, $9,19 \mathrm{~g} / 100 \mathrm{~g}$ de cálcio, $2,51 \mathrm{~g} / 100 \mathrm{~g}$ de fósforo e $6,74 \mathrm{mg} / \mathrm{g}$ de ferro. Esta farinha foi incluída nas diferentes rações experimentais. Todavia, não houve diferença estatística para a composição das rações.

Foi analisado o perfil de ácidos graxos da farinha de resíduos de filetagem de tilápia e das rações experimentais (Tabela 2). Os ácidos graxos majoritários encontrados nas rações foram 16:0 (ácido palmítico), 19,57\%, 19,98\%, 19,89\%, 20,55\%, 19,71\%; 18:0 (ácido esteárico), 2,20\%, $2,15 \%, 2,43 \%, 2,52 \%$ e $2,21 \% ; 18: 1 n 9 c$ (ácido oleico), 21,69\%, 21,68\%, 23,01\%,24,11\% e 24,05\%; e 18:2n6c (ácido linoléico), 48,26\%, 48,04\%, $46,66 \%, 42,33 \%$ e $45,47 \%$, respectivamente aos tratamentos $0 \%, 1 \%, 2 \%, 3 \%$ e $4 \%$ de inclusão de farinha de resíduos de filetagem de tilápia. 
Tabela 2. Perfil de ácidos graxos da farinha de resíduos de filetagem de tilápia (FRFT) e das rações experimentais.

\begin{tabular}{|c|c|c|c|c|c|c|}
\hline \multirow{2}{*}{ Ácidos graxos } & \multirow{2}{*}{ FRFT } & \multirow{2}{*}{ RT } & \multicolumn{4}{|c|}{ Níveis de inclusão de FRFT } \\
\hline & & & $1 \%$ & $2 \%$ & $3 \%$ & $4 \%$ \\
\hline $14: 0$ & 0,00 & 0,24 & 0,41 & 0,00 & 0,95 & 0,00 \\
\hline 15:0 & 0,00 & 0,00 & 0,00 & 0,00 & 0,18 & 0,00 \\
\hline 15:1 & 6,34 & 0,00 & 0,00 & 0,00 & 0,00 & 0,00 \\
\hline 16:0 & 24,97 & 19,57 & 19,98 & 19,89 & 20,55 & 19,71 \\
\hline $16: \ln 7$ & 3,47 & 0,00 & 0,00 & 0,00 & 0,00 & 0,00 \\
\hline $16: \ln 9 \mathrm{c}$ & 0,00 & 0,79 & 0,85 & 1,25 & 1,99 & 2,47 \\
\hline $17: 0$ & 0,00 & 0,00 & 0,00 & 0,00 & 0,26 & 0,00 \\
\hline $17: 1$ & 0,00 & 0,00 & 0,00 & 0,00 & 0,11 & 0,00 \\
\hline 18:0 & 6,41 & 2,20 & 2,15 & 2,43 & 2,52 & 2,21 \\
\hline $18: \ln 9 \mathrm{c}$ & 27,64 & 21,69 & 21,68 & 23,01 & 24,11 & 24,05 \\
\hline $18: 2 n 6 c$ & 14,99 & 48,26 & 48,04 & 46,66 & 42,33 & 45,47 \\
\hline $18: 3 n 3$ & 0,00 & 6,39 & 6,34 & 6,14 & 5,68 & 6,09 \\
\hline $20: 0$ & 0,00 & 0,25 & 0,29 & 0,25 & 0,20 & 0,00 \\
\hline $20: \ln 9$ & 0,00 & 0,00 & 0,00 & 0,36 & 0,33 & 0,00 \\
\hline 21:0 & 0,00 & 0,00 & 0,00 & 0,00 & 0,15 & 0,00 \\
\hline $20: 3 n 6$ & 0,00 & 0,00 & 0,00 & 0,00 & 0,25 & 0,00 \\
\hline $20: 4 \mathrm{n} 6$ & 7,30 & 0,00 & 0,00 & 0,00 & 0,28 & 0,00 \\
\hline $20: \ln 9$ & 0,00 & 0,00 & 0,27 & 0,00 & 0,00 & 0,00 \\
\hline $22: 6 n 3$ & 5,02 & 0,00 & 0,00 & 0,00 & 0,12 & 0,00 \\
\hline 24:1n9 & 3,85 & 0,00 & 0,00 & 0,00 & 0,00 & 0,00 \\
\hline$\sum \mathrm{AGS}$ & 31,38 & 22,01 & 22,83 & 22,57 & 24,80 & 21,92 \\
\hline$\sum \mathrm{AGMI}$ & 41,31 & 22,48 & 22,79 & 24,62 & 26,54 & 26,52 \\
\hline$\sum$ AGPI & 27,31 & 54,65 & 54,38 & 52,80 & 48,65 & 51,56 \\
\hline$n-3$ & 5,02 & 6,39 & 6,34 & 6,14 & 5,79 & 6,09 \\
\hline$n-6$ & 22,29 & 48,26 & 48,04 & 46,66 & 42,86 & 45,47 \\
\hline AGPI/AGS & 0,87 & 2,48 & 2,38 & 2,34 & 1,96 & 2,35 \\
\hline$n-6 / n-3$ & 4,44 & 7,55 & 7,57 & 7,60 & 7,40 & 7,46 \\
\hline
\end{tabular}

RT = ração testemunha; AGS = ácidos graxos saturados; AGMI = ácidos graxos monoinsturados; AGPI = ácidos graxos poliinsaturados; n-3 = ômega 3; n-6 = ômega 6 .

Fonte: Elaboração dos autores.

Boscolo (2003) analisou o perfil de ácidos graxos da farinha de resíduos da indústria de filetagem de tilápias encontrou valores distintos aos obtidos no presente experimento. $\mathrm{O}$ autor relatou que a farinha de peixe continha $18,38 \%$ de graxos poliinsaturados, $34,54 \%$ de ácidos graxos saturados, $15,93 \%$ de ácidos graxos n-6 e 3,78\% ácido graxo n-3. Neste experimento, com inclusão de farinha de resíduos de filetagem de tilápia na dieta de coelhos, verificou-se valores superiores aos relatados pelo autor para ácidos graxos poliinsaturados, 27,31\%, ácidos graxos n-6, 22,29\% e ácidos graxos n-3,
$5,02 \%$, entretanto, o teor de ácidos graxos saturados observados neste experimento foi inferior, $31,38 \%$,

Os valores obtidos nas análises de composição centesimal e mineral dos músculos dos coelhos submetidos aos diferentes níveis de inclusão da farinha de peixe estão na Tabela 3. Comparando os resultados da composição química dos músculos dos coelhos alimentados com a ração testemunha, com as demais rações contendo farinha de resíduos de filetagem de tilápia foram observadas diferenças $(\mathrm{P}>0,05)$ para umidade, proteína bruta e lipídeos. 
Tabela 3. Umidade, proteína bruta, lipídeos e cinzas nos músculos dos coelhos alimentados com rações contendo diferentes níveis de inclusão de farinha de resíduos de filetagem de tilápia (FRFT).

\begin{tabular}{lrrrrrrr}
\hline \multirow{2}{*}{ Composição química } & \multirow{2}{*}{ RT } & \multicolumn{4}{c}{ Níveis de inclusão da FRFT } & \multirow{2}{*}{ Médias } & \multirow{2}{*}{ CV\% } \\
\cline { 3 - 6 } & & \multicolumn{1}{c}{$2 \%$} & $3 \%$ & $4 \%$ & & \\
\hline Umidade (\%) & 79,81 & 74,33 & 75,17 & 66,25 & 75,56 & 74,62 & 0,15 \\
Proteína Bruta (\%) & 18,05 & 22,81 & 22,80 & 30,17 & 17,29 & 22,06 & 5,25 \\
Lipídeos (\%) & 7,09 & 6,94 & 6,36 & 10,03 & 6,97 & 7,47 & 17,78 \\
Cinzas (\%) & 1,05 & 1,04 & 1,10 & 1,14 & 1,07 & 1,08 & 3,76 \\
\hline
\end{tabular}

$\mathrm{RT}=$ ração testemunha;

Fonte: Elaboração dos autores.

Com a inclusão da farinha na ração dos coelhos, os músculos destes apresentaram menor teor de umidade, variando de $66,25 \%$ a $75,56 \%$, enquanto a umidade do tratamento testemunha foi de $79,81 \%$. Efeitos quadráticos foram encontrados para os valores de proteína bruta, cuja equação foi $\hat{\mathrm{y}}=9,83+14,79 \mathrm{Xi}-3,28 \mathrm{Xi}^{2}, \quad \mathrm{R}^{2}=0,6 \quad(\mathrm{P}<0,0001)$, e para umidade $\hat{y}=80,53-8,024 X i+1,69 \mathrm{Xi}^{2}, \mathrm{R}^{2}=$ $0,71 \quad(\mathrm{P}<0,0001)$. Quanto aos lipídios, somente os músculos dos coelhos que receberam 3\% da inclusão da farinha apresentaram valor superior ao encontrado nos músculos que receberam tratamento controle, evidenciando diferença estatística do tratamento com $0 \%$ de inclusão de farinha de resíduos de filetagem de tilápia do Nilo. Quando analisados os ácidos graxos da farinha deste mesmo tratamento (Tabela 2), os valores dos ácidos graxos majoritários foram superiores aos demais tratamentos, exceto para o ácido linoléico $(42,33 \%)$ e linolênico $(5,68 \%)$, isto porque a farinha de peixe é pobre em ácido linolênico, e com o aumento da quantidade de farinha de peixe na ração proporcionou menores teores destes na ração e também deve se levar em consideração a granulometria da farinha utilizada e a dificuldade que houve quanto à obtenção do tamanho homogêneo das partículas da farinha de peixe. Com a redução dos níveis de farelo de soja nas rações onde foram incluídos os níveis de farinha de peixe houve uma redução dos dois ácidos graxos mencionados (Tabela 2).

Os valores de cinzas da carcaça não apresentaram diferenças entre os níveis de inclusão da farinha de resíduos de filetagem de tilápia do Nilo e a ração testemunha, comprovando que os diferentes níveis de inclusão da farinha não influenciaram a deposição quantitativa de minerais no tecido muscular dos coelhos.

De acordo com o Guia de la cunicultura (2004), os músculos de coelhos apresentam $68 \%$ a $71,70 \%$ de umidade, $20,30 \%$ a $21,10 \%$ de proteína bruta; $5,53 \%$ a $10 \%$ de lipídios e $1,05 \%$ a $1,11 \%$ de cinzas. Os mesmos autores relatam que o músculo de coelho apresenta em média de $22,8 \mathrm{mg} / 100 \mathrm{~g}$ de cálcio, $200-253 \mathrm{mg} / 100 \mathrm{~g}$ de fósforo e $1,5 \mathrm{mg} / 100 \mathrm{~g}$ de ferro.

Quando se analisou os minerais individualmente pode-se observar que houve variação significativa $(\mathrm{P}<0,05)$. Os valores dos minerais (cálcio e fósforo), nos músculos dos coelhos alimentados com rações contendo diferentes níveis de farinha de resíduos de filetagem de tilápia, diferiram dos animais que receberam a ração testemunha $(\mathrm{P}<0,05)$. A fonte de cálcio utilizada para a formulação da ração influencia na deposição do cálcio no músculo dos animais, e a medida que aumenta o nível de inclusão há tendência de aumentar o nível de deposição. Todavia, neste experimento em função da dificuldade que houve em obter homogeneidade no tamanho das partículas da própria farinha de peixe, pode-se perceber que em 3 e $4 \%$ os valores foram menores. Para o ferro presente no músculo, não houve diferença estatística devido aos percentuais da ração serem próximos entre eles e não ter diferença em termos de absorção do ferro em função a sua fonte de origem, conforme 
consta na Tabela 4. Realizando a análise de regressão de cálcio e fósforo dos músculos dos animais que receberam ração com inclusão da farinha, houve efeito quadrático. Este efeito deve-se provavelmente ao tamanho heterogêneo das partículas de farinha de peixe na ração. As equações foram $\hat{y}=26,6+10,2 \mathrm{Xi}-$ $2,20 \mathrm{Xi}^{2}, \mathrm{R}^{2}=0,71 ; \hat{\mathrm{y}}=153,31-52,19 \mathrm{Xi}+12,30 \mathrm{Xi}^{2}, \mathrm{R}^{2}$ $=0,77$.

Tabela 4. Cálcio, fósforo e ferro nos músculos dos coelhos alimentados com rações contendo diferentes níveis de inclusão de farinha de peixe proveniente dos resíduos filetagem (FRFT).

\begin{tabular}{lccccccc}
\hline \multirow{2}{*}{ Minerais } & \multirow{2}{*}{ RT } & \multicolumn{3}{c}{ Níveis de inclusão de FRFT } & \multirow{2}{*}{ Médias } & \multirow{2}{*}{ CV\% } \\
\cline { 3 - 6 } & & $1 \%$ & $2 \%$ & $3 \%$ & $4 \%$ & & \\
\hline Cálcio $(\mathrm{mg} / 100 \mathrm{~g})$ & 28,00 & 31,00 & $42,00^{*}$ & $35,00^{*}$ & 32,00 & 33,60 & 13,06 \\
Fósforo $(\mathrm{mg} / 100 \mathrm{~g})$ & 112,00 & 110,40 & 104,20 & 100,80 & $148,40^{*}$ & 115,16 & 17,60 \\
Ferro $(\mathrm{mg} / 100 \mathrm{~g})$ & 1,98 & 1,77 & 2,01 & 1,92 & 1,95 & 1,93 & 14,17 \\
\hline
\end{tabular}

$\mathrm{RT}=$ ração testemunha; $*$ = difere da testemunha pelo teste de Dunnet $(\mathrm{P}>0,05)$

Fonte: Elaboração dos autores.

Vitti et al. (2006), realizaram um experimento para avaliar o metabolismo do cálcio em ovinos em crescimento. Utilizaram diferentes fontes de cálcio nas rações e encontraram valores diferentes na quantidade de cálcio/g do músculo dos ovinos. Para os ovinos que receberam como fonte de cálcio, a polpa cítrica, o teor de cálcio presente no músculo foi de $3,16 \%$, enquanto para os animais que receberam calcário calcítico e farinha de conchas de ostras, os teores foram inferiores, $1,85 \%$ e $1,97 \%$, respectivamente. Estes valores mostram que a fonte de cálcio utilizada para a formulação da ração influencia na deposição do cálcio no músculo dos animais.

Os valores dos ácidos graxos presentes no músculo dos coelhos alimentados com farinha de resíduos de filetagem de tilápia estão na Tabela 5. Os ácidos graxos majoritários presentes nos músculos dos coelhos foram o ácido palmítico (16:0), que variou de $19,18 \%$ a 21,01\%, ácido oléico (18:1n9) de $16,71 \%$ a $18,71 \%$ e o ácido linoléico (18:2n6) de $28,83 \%$ a $30,85 \%$.
Não houve variação no somatório dos ácidos graxos saturados, ficando entre $29,05 \%$ e $31,46 \%$, porém no somatório dos ácidos graxos poliinsaturados houve um acréscimo de 37,68\% para aproximadamente $40 \%$, à medida que aumentou a inclusão do nível da farinha de resíduos de filetagem de tilápia na ração, de $0 \%$ a $2 \%$, em que permaneceu até os $4 \%$ de inclusão da farinha. Os ácidos graxos monoinsaturados variaram de $28,53 \%$ a $31,07 \%$ entre os tratamentos dos animais que receberam a inclusão da farinha de resíduos de filetagem de tilápia, enquanto no tratamento testemunha foi de $31,61 \%$. Quanto a relação de ácidos graxos poliinsaturados:ácidos graxos saturados, não houve variações, cujos valores foram de $1,27 \%$ a $1,37 \%$ nos tratamentos com inclusão da farinha de resíduos de filetagem de tilápia. Estes resultados estão de acordo com o Departamento de saúde e seguridade social da inglaterra (1994), que define que razões de AGPI/AGS inferiores a $0,45 \%$ são pouco aconselháveis para a saúde podendo ocasionar doenças cardíacas. 
Tabela 5. Valores de ácidos graxos, nos músculos de coelhos, alimentados com rações contendo diferentes níveis de farinha de resíduo de filetagem de tilápia (FRFT).

\begin{tabular}{|c|c|c|c|c|c|}
\hline \multirow{2}{*}{$\begin{array}{l}\text { Ácidos } \\
\text { Graxos }\end{array}$} & \multirow{2}{*}{ RT } & \multicolumn{4}{|c|}{ Níveis de inclusão da FRFT } \\
\hline & & $1 \%$ & $2 \%$ & $3 \%$ & $4 \%$ \\
\hline $10: 0$ & 0,57 & 1,37 & 0,97 & 1,11 & 1,79 \\
\hline 12:0 & 0,36 & 0,73 & 0,48 & 0,56 & 1,00 \\
\hline 14:0 & 1,90 & 2,88 & 2,18 & 2,36 & 2,74 \\
\hline $14: 1$ & 0,27 & 0,35 & 0,30 & 0,00 & 0,00 \\
\hline 15:0 & 0,40 & 0,45 & 0,41 & 0,38 & 0,49 \\
\hline $15: 1$ & 4,93 & 4,88 & 4,41 & 5,27 & 5,55 \\
\hline 16:0 & 20,61 & 19,60 & 21,01 & 19,18 & 19,33 \\
\hline $16: \ln 9$ & 5,08 & 5,32 & 4,84 & 5,07 & 4,64 \\
\hline 17:0 & & 47 & 82 & 0,42 & 1,41 \\
\hline $7: 1$ & 26 & 1,10 & 1,34 & 1,53 & 1,63 \\
\hline 18:0 & 61 & 3,91 & 4,09 & 4,13 & 3,82 \\
\hline $18: 1 \mathrm{n} 9 \mathrm{c}$ & 9,43 & 18,49 & 17,03 & 18,71 & 16,71 \\
\hline $18: 2 \mathrm{n} 6 \mathrm{c}$ & 33,12 & 30,85 & 28,83 & 30,47 & 31,32 \\
\hline $18: 3 n 3$ & 3,51 & 3,37 & 5,59 & 3,01 & 3,27 \\
\hline$: \ln 9$ & ,26 & 0,20 & 0,1 & 0,00 & 0,00 \\
\hline $20: 2$ n6 & ,39 & 3,99 & 0,0 & 0,00 & 0,00 \\
\hline $24: 0$ & & 1,02 & 1,07 & 0,91 & 0,88 \\
\hline 4:1n9 & 0,38 & 0,46 & 0,00 & 0,50 & 0,00 \\
\hline $22: 5 n 3$ & 0,66 & 0,55 & 0,00 & 0,00 & 0,00 \\
\hline $20: 3 n 3$ & 0,00 & 0,00 & 0,00 & 0,00 & 0,66 \\
\hline 20:3n6 & 0,00 & 0,00 & 0,63 & 0,67 & 0,00 \\
\hline 20:4n6 & 0,00 & 0,00 & 4,56 & 4,92 & 4,14 \\
\hline $24: \ln 9$ & & 0,00 & 0,60 & 0,00 & 0,00 \\
\hline $22: 6 n 3$ & 0,00 & 0,00 & 0,69 & 0,81 & 0,62 \\
\hline$\sum \mathrm{AGS}$ & 30,71 & 30,42 & 31,04 & 29,05 & 31,46 \\
\hline$\sum \mathrm{AGMI}$ & 31,61 & 30,8 & 28,68 & 31,07 & 28,53 \\
\hline$\sum$ AGPI & 37,68 & 38,77 & 40,29 & 39,88 & 40,01 \\
\hline$n-3$ & & 3,93 & 6,28 & 3,83 & 4,55 \\
\hline$n-6$ & 33,51 & 34,84 & 34,01 & 36,05 & 35,46 \\
\hline AGPI/AGS & 1,23 & 1,27 & 1,3 & 1,37 & 1,27 \\
\hline$n-6 / n-3$ & 8,04 & 8,87 & 5,42 & 9,42 & 7,8 \\
\hline
\end{tabular}

RT = ração testemunha; AGS = ácidos graxos saturados; AGMI $=$ ácidos graxos monoinsturados; AGPI = ácidos graxos poliinsaturados; n-3 = ômega 3; n-6 = ômega 6 .

Fonte: Elaboração dos autores.

Guia de la cunicultura (2004) relata sobre a quantidade total de ácidos graxos no músculo de coelhos, sendo a somatória de ácidos graxos saturados de $36,20 \%$ e ácidos graxos poliinsaturados de $26,50 \%$.
Silva et al. (2009), realizaram um trabalho com coelhos desmamados em diferentes idades, recebendo dietas com ou sem inclusão de óleo de soja. Com relação aos ácidos graxos monoinsaturados presente no músculo dos coelhos, apenas os ácidos cis 9-hexadecenoico $(16: 1 n 7)$ e o 8 -heptadecanoico $(17: \ln 9)$ tiveram seus níveis reduzidos. Entre os ácidos graxos poliinsaturados, a adição de óleo de soja na dieta da desmama ao abate elevou os teores dos ácidos 9,12-octadecadienoico (18:2n6) e do 9,12,15-octadecatrienoico (18:3n3), o que resultou em níveis maiores, tanto no somatório dos ácidos graxos dos grupos n-6 passando de $29,38 \%$ para $32,90 \%$. Neste experimento, com a inclusão de farinha de resíduos de filetagem de tilápia na dieta de coelhos, também houve um acréscimo no somatório dos ácidos graxos do grupo n-6, passando de $33,51 \%$ nos animais recebendo $0 \%$ de inclusão de farinha de peixe para $36,05 \%$ no tratamento que recebeu 3\% de inclusão da farinha de resíduos de filetagem de tilápia. Os mesmos autores também relataram sobre o aumento na relação de ácidos graxos poliinsaturados:saturados, que foi alterada de 0,73 (sem inclusão) para 1,14 com a inclusão de $2,5 \%$ óleo de soja. Neste trabalho também obteve-se resultados semelhantes, ocorrendo um acréscimo na relação AGPI:AGS, entre os coelhos que não receberam inclusão de farinha de peixe na ração 1,23 e os coelhos que receberam 3\% de inclusão da farinha 1,37 , portanto um acréscimo de $11,38 \%$, com a inclusão de farinha de resíduos de filetagem de tilápia na ração. Isto ocorreu em função de que a composição de ácidos graxos é influenciada pela alimentação (VICENTE NETO, 2005).

O perfil de ácidos graxos dos músculos do coelho também foi descrito por Colin et al. (2007), que relataram os somatórios dos valores de ácidos graxos saturados $(36,80 \%)$, ácidos graxos monoinsaturados $(34,20 \%)$, ácidos graxos poliinsaturados $(28,20) \%$, ácidos graxos n-6 (26,50\%) e ácidos graxos n-3 (1,60\%). Hurlan et al. 
(1989), trabalhando com diferentes níveis de farinha de peixe na ração $(0 \%, 4 \%, 8 \%$ e $12 \%)$ de frango de corte, perceberam que $12 \%$ de inclusão da farinha de peixe poderiam contribuir com $197 \mathrm{mg}$ de n-3 em cada $100 \mathrm{~g}$ de carne. Neste experimento, houve um acréscimo no valor de ácidos graxos n-3 no músculo de coelhos alimentados com a ração contendo $2 \%$ de inclusão da farinha, passando de 4,17\% nos músculos dos coelhos que receberam ração sem inclusão da farinha, para 6,28\% (acréscimo de $50,59 \%$ ) no músculo dos animais alimentados com 2\% de inclusão da farinha na ração.
Os valores de cálcio, fósforo, ferro, cinzas e resistência óssea do fêmur dos coelhos estão na Tabela 6. Os valores de matéria mineral do fêmur dos coelhos alimentados com farinha de resíduos de filetagem de tilápia não diferiram dos coelhos alimentados sem a inclusão da farinha $(\mathrm{P}<0,05)$, este resultado também foi observado para os minerais (cálcio, fósforo e ferro) e para a resistência óssea. A média das cinzas encontradas nos ossos foi de 52,47 $\%$, a média do teor de cálcio foi de $20,36 \mathrm{~g} / 100 \mathrm{~g}$, do fósforo foi de $0,17 \mathrm{~g} / 100 \mathrm{~g}$, do ferro $0,17 \mathrm{mg} / \mathrm{g}$ e para resistência óssea foi de 23,40 Kgf.

Tabela 6. Cálcio, fósforo, ferro, cinzas e resistência óssea do fêmur dos coelhos alimentados com ração contendo níveis de inclusão da farinha de resíduos de filetagem de tilápia (FRFT).

\begin{tabular}{lccccccc}
\hline & \multirow{2}{*}{ RT } & \multicolumn{3}{c}{ Níveis de inclusão da FRFT } & \multirow{2}{*}{ Médias } & \multirow{2}{*}{ CV\% } \\
\cline { 3 - 6 } & & $1 \%$ & $2 \%$ & $3 \%$ & $4 \%$ & & \\
\hline Cálcio $(\mathrm{g} / 100 \mathrm{~g})$ & 19,23 & 20,47 & 20,68 & 20,90 & 20,53 & 20,36 & 3,22 \\
Fósforo(g/100g) & 0,19 & 0,18 & 0,17 & 0,16 & 0,15 & 0,17 & 9,46 \\
Ferro (mg/g) & 0,18 & 0,17 & 0,18 & 0,17 & 0,17 & 0,17 & 2,94 \\
Cinzas (\%) & 52,34 & 52,30 & 52,02 & 53,09 & 52,61 & 52,47 & 0,76 \\
Resistência (Kgf) & 23,24 & 24,08 & 24,50 & 23,22 & 21,95 & 23,40 & 11,78 \\
\hline
\end{tabular}

RT = Ração testemunha

Fonte: Elaboração dos autores.

Sá et al. (2004), relataram a exigência nutricional de cálcio para frangos de corte, nas fases de crescimento e terminação. Os autores utilizaram diferentes níveis de cálcio na ração $(0,16 \%$, $0,41 \%, 0,66 \%, 0,99 \%, 1,16 \%$ e $1,41 \%$ ) e relataram que a resistência óssea foi alterada, havendo um acréscimo à medida que aumentou a inclusão de cálcio na ração $(8,15 \mathrm{Kfg}, 16,91 \mathrm{Kgf}, 22,24 \mathrm{Kgf}$, $31,03 \mathrm{Kgf}, 31,76 \mathrm{Kgf}$ e $31,46 \mathrm{Kgf}$ respectivamente). Comparando os resultados apresentados pelos autores com os deste experimento, quanto a resistência óssea, pode-se observar que nos níveis de cálcio $0,16 \%, 0,41 \%$ e $0,66 \%$ a resistência óssea dos frangos foi inferior aos obtidos neste experimento com coelhos, porém nos níveis $0,99 \%, 1,16 \%$ e $1,41 \%$ de cálcio, a resistência foi superior. $\mathrm{O}$ fato do excesso de cálcio consumido pelos coelhos ser excretado pela urina, conforme relatado por Pêssoa (2003) pode ter contribuído pela não deposição de mais cálcio nos ossos.

Novos estudos devem ser realizados com a inclusão da farinha de resíduos de filetagem de tilápia na produção animal, analisando novas metodologias no processamento da farinha, bem como a redução da granulometria da farinha, também maiores níveis de inclusão da mesma na ração dos animais a serem avaliados e um maior período experimental.

A inclusão da farinha de resíduos de filetagem de tilápia avaliada neste estudo é uma opção de alimento para a produção animal, já que apresenta ácidos graxos majoritários 16:0, 18:1n9 e 18:2n6 e minerais (cálcio e fósforo). Os animais que receberam ração com $2 \%$ e $3 \%$ de inclusão da farinha apresentaram maior nível de cálcio no músculo. 
Entretanto, a inclusão da farinha não influenciou na resistência óssea, matéria mineral, cálcio, fósforo e ferro dos ossos.

\section{Referências}

BLIGH, E. G.; DYER, W. J. A rapid method of total lipid extraction and purification. Canadian Journal of Biochemistry, Ottawa, v. 37, p. 911-17, 1959.

BORGHETTI, N. R. B.; OSTRENSKY, A.; BORGHETTI, J. R. Aqüicultura: uma visão geral sobre a produção de organismos aquáticos no Brasil e no mundo. Curitiba: Grupo Integrado de Aqüicultura e Estudos Ambientais, 2003. 128 p.

BOSCOLO, W. R. Farinha de resíduo da industria de filetagem de tilápias na alimentação da tilápia do Nilo (Oreochromis niloticus L.). 2003. Tese (Doutorado em Zootecnia) - Universidade Estadual de Maringá, Maringá.

BOSCOLO, W. R.; HAYASHI, C.; SOARES, C. M.; FURUYA, W. M.; MEURER, F. Desempenho e características de carcaça de machos revertidos de tilápias do Nilo (Oreochromis niloticus), linhagens tailandesa e comum, nas fases iniciais e de crescimento. Revista Brasileira de Zootecnia, Viçosa, v. 30, n. 5, p. 1391-1396, 2001.

COLIN, M.; RAGUENES, N.; LE BERRE, G.; PRINGENT, A. Y. Influência de um enriquecimento de alimento de ácidos gordos Ómega 3, provenientes de grã de linho extrudido (Tradi-Lin), sobre os lipídeos e as características da carne de coelho. In: CONGRESSO IBÉRICO DE CULNICULTURA, 2., 2007, Vila Real. Anais... Vila Real: Associacion Española de Cunocultura, 2007. p. 21-25.

CUNNIFF, P. A. Official methods of analysis of AOAC international. Arlington: Association of Official Analytical Chemists, 1998. 240 p.

DE BLAS, C.; MATEOS, G. G. Feed Formulation. In: DE BLAS, C.; WISEMAN, J. (Ed.). The nutrition of the rabbit. London: Cab Publishing, 1998. p. 241-253.

EIJSINK, L. M.; KROM, M. D.; LANGE, G. J. The use of sequential extraction techniques for sedimentary phosphorus in eastern Mediterranean sediments. Marine Geology, Morehead City, v. 139, n. 14, p. 147-155, 1997.

EYNG, C.; NUNES, R. V.; POZZA, P. C.; SILVA, W. T. M.; NAVARINI, F. C.; HENZ, J. R. Farinha de resíduos da indústria de filetagem de tilápias em rações para frangos de corte. Revista Brasileira de Zootecnia, Viçosa, v. 39, n. 12, p. 2670-2675, 2010.
FERREIRA, W. M.; FERREIRA, S. R. A.; CASTRO EULER, A. C. C.; MACHADO, L. C.; OLIVEIR, A. C. E. A.; VASCONCELOS, C. H. F. Avanços na nutrição e alimentação de coelhos no Brasil. In: ZOOTEC, 2., 2006, Recife. Resumos... Recife: Zootec, 2006. CD-ROM.

GODOY, L. C. Farinha de carcaça de peixe com ervas aromáticas para alimentação humana. 2006. Trabalho de conclusão de curso (Graduação em Zootecnia) Universidade Estadual de Maringá, Maringá.

GUIA DE LA CUNICULTURA. Guia 2005 de la cunicultura. Barcelona: Real Escuela de Avicultura, 2004. p. 83-90.

HARDY, R. W. Alternate protein sources for salmon and trout diets. Animal Feed Science Technology, Amsterdam, v. 59, n. 1-3, p. 71-80, 1996.

HURLAN, H. W.; ACKMAN, R. G.; RATNAYAKE, W. M. N.; PROUDFOOT, F. G. Omega-3 fatty acid levels and general performance of commercial broilers fed practical levels of redfish meal. Poultry Science, Savoy, v. 68, n. 1, p. 153-162, 1989.

INTERNATIONAL ORGANIZATION FOR STANDARDIZATION - ISO. Animal and vegetable fats and Oils- Preparation of methyl esters of fatty acids. Geneve: ISO 5509, 1978. p. 1-6.

MACHADO, L. C.; FERREIRA, W. M.; SCAPINELLO, C.; PADIlHA, M. T. S.; EULER, A. C. C. Manual de formulação de ração e suplementos para coelhos. Bambuí: Associação Científica Brasileira de Cunicultura, 2011. 24 p.

NAYLOR, R. L.; GOLDBURG, R. J.; PRIMAVERA, J. H.; KAUTSKY, N.; BEVERIDGE, M. C.; CLAY, J.; FOLKE, C.; DUBCHENCO, J.; MOONEY, H.; TROLLE, M. Effect of aquaculture on world fish supplies. Nature, Londres, v. 405, n. 1, p. 1017-1024, 2000.

PÊSSOA, M. F. Avaliação nutricional de diferentes rações comerciais em coelhos em crescimento. 2003. Dissertação (Mestrado) - Universidade Federal Rural do Rio de Janeiro, Rio de Janeiro.

SÁ, L. M.; GOMES, P. C.; ROSTAGNO, H. S.; ALBINO, L. F. T.; CECON, P. R.; D’AGOSTINI, P. Exigência nutricional de cálcio para frangos de corte, nas fases de crescimento e terminação. Revista Brasileira Zootecnia, Viçosa, v. 33, n. 2, p. 397-406, 2004.

SAS Institute. The SAS systems for windows. Realease 8.01. Cary, 2000.

SILVA, A. J. I. Composição lipídica e quantificação dos ácidos graxos poliinsaturados EPA (20:5 n-3) e DHA (22:6n-3) de peixes de água doce. 2000. Tese (Doutorado em Engenharia de Alimentos) - Universidade Estadual de Campinas, Campinas. 
SILVA, D. J.; QUEIROZ, A. C. Análise de alimentos: métodos químicos e biológicos. Viçosa: Universidade Federal de Viçosa, 2002. 235 p.

SILVA, W. R.; SCAPINELLO, C.; FURLAN, A. C.; MURAKAMI, A. E.; MOREIRA, I.; MARTINS, E. N. Perfil de ácidos graxos da carcaça de coelhos desmamados em diferentes idades e condições de alimentação, recebendo dietas com ou sem óleo de soja. Animal Science-Acta Scientiarum, Maringá, v. 31, n. 3, p. 257-263, 2009.

SUGIURA, S. H.; BABBITT, J. K.; DONG, F. M.; HARDY, R. W. Utilization of fish and animal byproduct meals in low-pollution feeds for rainbow trout Oncorhynchus mykiss (Walbaum). Aquaculture Research, New York, v. 31, n. 7, p. 585-593, 2000.

VICENTE NETO, J. Caracterização físico química, colesterol e ácidos graxos da carne de jacaré-dopantanal (Caiman yacare Daudin 1802) oriundo de zoocriadouro e habitat natural. 2005. Dissertação (Mestrado em Ciência dos Alimentos) - Universidade Federal de Lavras, Lavras.
VIDOTTI, R. M.; GONÇALVES, G. S. Produção e caracterização de silagem, farinha e óleo de tilápia e sua utilização na alimentação animal. Instituto de Pesca, São Paulo, out. 2006. Disponível em: <hftp://www.sp.gov.br/ ftppesca/producao_caracterizacao.pdf $>$. Acesso em: 28 nov. 2011.

VISENTAINER, J. V. Composição de ácidos graxos e quantificação dos ácidos LNA, EPA e DHA no tecido muscular de tilápias (Oreochromis niloticus), submetidas a diferentes tratamentos com óleo de linhaça. 2003. Tese (Doutorado em Ciência de Alimentos) - Universidade Estadual de Campinas, Campinas.

VITTI, D. M. S. S.; ROQUE, A. P.; DIAS, R. S.; LOPES, J. B.; BUENO, I. C. S.; BUENO, M. S.; NOZELLA, E. F. Metabolismo de cálcio em ovinos em crescimento sob suplementação com diferentes fontes de cálcio: aplicação e comparação de dois modelos matemáticos. Revista Brasileira Zootecnia, Viçosa, MG, v. 35, n. 6, p. 24872495, 2006.

ZHOU, H. Y.; CHENG, R. Y. H.; CHAN, K. M.; WONG, M. H. Metal concentrations in sediments and tilapia collected from Island water of Hong Kong. Water Research, Olso, v. 32, n. 11, p. 3331-3340, 1998. 